\title{
Glycyrrhizic acid induces apoptosis in WEHI-3 mouse leukemia cells through the caspase- and mitochondria-dependent pathways
}

\author{
FU-SHIN CHUEH $^{1 *}$, YUNG-TING HSIAO ${ }^{2 *}$, SHU-JEN CHANG ${ }^{4}$, PING-PING WU ${ }^{4}$, \\ JAI-SING YANG ${ }^{3}$, JEN-JYH LIN ${ }^{5,6}$, JING-GUNG CHUNG ${ }^{2}$ and TUNG-YUAN LAI ${ }^{7,8}$ \\ ${ }^{1}$ Department of Health and Nutrition Biotechnology, Asia University, Taichung; Departments of ${ }^{2}$ Biological Science
and Technology and ${ }^{3}$ Pharmacology, ${ }^{4}$ School of Pharmacy, ${ }^{5}$ Graduate Institute of Chinese Medicine, China
Medical University, Taichung; ${ }^{6}$ Division of Cardiology, China Medical University Hospital, Taichung;
${ }^{7}$ Department of Traditional Medicine, Wan Fang Hospital, Taipei Medical University, Taipei; ${ }^{8}$ Graduate
Institute of Pharmacognosy, College of Pharmacy, Taipei Medical University, Taipei, Taiwan, R.O.C.
}

Received June 1, 2012; Accepted August 7, 2012

DOI: 10.3892/or.2012.2029

\begin{abstract}
Leukemia, one of the causes of cancer-related death in humans, is an aggressive malignancy via the rapid growth of abnormal white blood cells. The aim of this study was to determine the anti-leukemia effect of glycyrrhizic acid (GA) on a mouse leukemia cell line, WEHI-3. GA, an active compound in Glycyrrhiza glabra, has been proven to induce cytotoxic effects in many cancer cell lines. In the current study, we investigated the effects of GA in mouse leukemia cells in vitro. The results indicated that GA induced morphological changes, $\mathrm{G}_{0} / \mathrm{G}_{1}$ phase arrest, apoptosis and DNA damage in WEHI- 3 cells as determined by phase contrast microscopy, DAPI-staining, flow cytometry and comet assay. The results from the flow cytometric assay showed that GA increased ROS levels, reduced the mitochondrial membrane potential $(\Delta \Psi \mathrm{m})$ and stimulated caspase-3 activity in WEHI-3 cells. GA regulated the intrinsic and extrinsic apoptosis-associated protein expression which was determined by western blotting. In addition, endoplasmic reticulum (ER) stress responses were observed in GA-treated WEHI-3 cells. GA promoted the trafficking of apoptosis-inducing factor (AIF), cytochrome $c$ and endonuclease G (Endo G) in WEHI-3 cells. Based on this evidence, GA-triggered apoptosis occurs through the
\end{abstract}

Correspondence to: Dr Tung-Yuan Lai, Department of Traditional Medicine, Wan Fang Hospital, Taipei Medical University, No. 111, Section 3, Hsing-Long Road, Taipei 116, Taiwan, R.O.C.

E-mail: 100322@w.tmu.edu.tw

${ }^{*}$ Contributed equally

Key words: glycyrrhizic acid, murine leukemia WEHI-3 cells, apoptosis, mitochondria, ER stress death receptor, mitochondria-mediated and ER stress multiple signaling pathways.

\section{Introduction}

Leukemia is one of the causes of cancer-related death in humans $(1,2)$. According to the Department of Health, Executive Yuan, Taiwan R.O.C. (2010), approximately 4.2 per 100,000 people in Taiwan succumb to leukemia each year $(3,4)$. Currently, treatment of leukemia in clinics includes hematopoietic stem cell transplantation, radiotherapy and chemotherapy agents; however, these outcomes are not fully satisfactory (5-7). Thus, numerous studies have been focused on discovering a novel compound from natural products that blocks the development of cancer, including leukemia. The most effective strategy for killing cancer cells is to induce apoptosis. Evidence has shown that increased consumption of a plant-based diet may reduce the risk of cancer $(8,9)$.

For a number of years, Glycyrrhiza glabra (Licorice) has been used as a traditional Chinese medicine for the treatment of liver disease. It was reported that glycyrrhizic acid (GA) and $18 \beta$-glycyrrhetinic acid are the biologically active compounds in Licorice (10). GA, one of the triterpenoid saponin glycoside, was found to protect PC12 cells from 1-methyl-4-phenylpyridinium-induced cytotoxicity (11). GA alters inflammatory processes by modulating NF- $\mathrm{kB}$ activities (12) and by blocking the activation of NF- $\kappa B$ in primary neurons (13). Furthermore, it was reported that the neuroprotective effects of GA in PC12 cells is via modulation of the PI3K/Akt pathway (14). GA was found to modulate critical end points of oxidative stressinduced apoptosis and may be beneficial against liver diseases (15). Recently, it was reported that GA exerts an anti-inflammatory effect, at least in part, by inhibiting HMGB1 secretion (16). However, there is no available evidence demonstrating that GA induces apoptosis in leukemia cells. Therefore, the present study investigated the effects of GA on the cytotoxicity of mouse leukemia cells (WEHI-3). Our findings indicated that 
GA induced apoptosis in WEHI-3 cells through caspase- and mitochondria-dependent pathways.

\section{Materials and methods}

Chemicals and reagents. GA, agarose, 4,6-diamidino2-phenylindole dihydrochloride (DAPI), dimethyl sulfoxide (DMSO), propidium iodide (PI), Triton X-100, Tris- $\mathrm{HCl}$ and ribonuclease A were purchased from Sigma-Aldrich Corp. (St. Louis, MO, USA). 2',7'-Dichlorodihydrofluorescein diacetate ( $\mathrm{H}_{2}$ DCF-DA), 3,3'-dihexyloxacarbocyanine iodide $\left(\right.$ DiOC $\left._{6}\right)$, RPMI-1640 medium, fetal bovine serum (FBS), L-glutamine, trypsin-EDTA and penicillin/streptomycin were purchased from Invitrogen/Life Technologies (Carlsbad, CA, USA). The caspase-3 activity assay kit and the caspase-3-specific inhibitor (z-Asp-Met-Gln-Asp-fluoromethyl ketone; z-DEVD-fmk) were obtained from R\&D Systems (Minneapolis, MN, USA). Primary and secondary antibodies used for western blotting were purchased from Santa Cruz Biotechnology, Inc. (Santa Cruz, CA, USA).

Cell morphology and viability determined in WEHI-3 cells. WEHI-3 cells were placed in 24-well plates at a density of $2 \times 10^{5}$ cells/well overnight and were then incubated with 0 , $200,250,300,350$ and $400 \mu \mathrm{M}$ of $\mathrm{GA}$ at $37^{\circ} \mathrm{C}$, in $5 \% \mathrm{CO}_{2}$ and $95 \%$ air for 24 and $48 \mathrm{~h}$. In order to examine morphological changes, cells from each treatment were examined and images were captured under a phase-contrast microscope at a magnification of x200. Cells in each well were harvested, stained with PI $(5 \mu \mathrm{g} / \mathrm{ml})$ and then the total number of viable cells for all samples was determined using flow cytometry (BectonDickinson, San Jose, CA, USA) as previously described $(17,18)$.

Assay of cell cycle distribution using flow cytometry. WEHI-3 cells $\left(2 \times 10^{5}\right.$ cells $\left./ \mathrm{ml}\right)$ in 24 -well plates were incubated with $200,250,300,350$ and $400 \mu \mathrm{M}$ of GA and were incubated for 0,24 and $48 \mathrm{~h}$. Cells from each treatment were collected, fixed in $70 \%$ ethanol overnight, washed twice with PBS and re-suspended in $500 \mu 1$ of $192 \mathrm{mM} \mathrm{Na}_{2} \mathrm{HPO}_{4}, 4 \mathrm{mM}$ citric acid and $\mathrm{pH} 7.8$ at $25^{\circ} \mathrm{C}$ for $30 \mathrm{~min}$. Then all samples were individually stained with $0.5 \mathrm{ml}$ of PBS containing $1 \mathrm{mg} / \mathrm{ml}$ RNase and $10 \mu \mathrm{g} / \mathrm{ml}$ PI for $30 \mathrm{~min}$ in the dark and were directly analyzed using flow cytometry as previously described (18).

DAPI staining and comet assay for examining the DNA damage in WEHI-3 cells. Approximately $5 \times 10^{4}$ cells $/ \mathrm{ml}$ of WEHI-3 cells in 24-well plates were individually treated with $0,200,250,300,350$ and $400 \mu \mathrm{M}$ of GA for 24 and $48 \mathrm{~h}$. After incubation, all samples from each treatment were harvested. For DAPI staining, cells were stained with DAPI (4,6-diamidino-2-phenylindole dihydrochloride), examined and images were captured using a fluorescence microscope as previously described $(9,19)$. For comet assay, cells were harvested, isolated and examined for DNA damage by using the comet assay as previously described $(9,17)$.

DNA gel electrophoresis for DNA fragmentation of WEHI-3 cells. Approximately $1 \times 10^{6}$ cells $/ \mathrm{ml}$ of WEHI- 3 cells on $10-\mathrm{cm}$ dishes were individually treated with $0,200,250,300,350$ and $400 \mu \mathrm{M}$ of GA for 24 and $48 \mathrm{~h}$. At the end of incubation, all samples from each treatment were harvested for DNA isolation (Genomic DNA Purification kit; Genemark Technology Co., Ltd., Tainan, Taiwan) and DNA gel electrophoresis was performed to examine the DNA fragmentation as previously described $(20,21)$.

Flow cytometric detection of reactive oxygen species (ROS), mitochondrial membrane potential $(\Delta \Psi \mathrm{m})$ and caspase-3 activity. WEHI-3 cells were placed in 24-well plates at the density of $2 \times 10^{5}$ cells $/ \mathrm{ml}$ and were then exposed to $300 \mu \mathrm{M}$ of GA for indicated intervals of time. ROS and $\Delta \Psi \mathrm{m}$ were assessed by cell permeable probes $\mathrm{H}_{2}$ DCF-DA $(10 \mu \mathrm{M})$ and $\mathrm{DiOC}_{6}(500 \mathrm{nM})$ using a flow cytometer, respectively, as previously described $(9,22)$. Cells were pretreated with or without NAC ( $5 \mathrm{mM})$ or Z-VAD-FMK $(5 \mu \mathrm{M})$, were incubated with $300 \mu \mathrm{M}$ GA for various time periods and were then harvested and lysed in a lysis buffer [50 mM Tris- $\mathrm{HCl}(\mathrm{pH} 7.4), 1 \mathrm{mM}$ EDTA, $10 \mathrm{mM}$ EGTA, $10 \mathrm{mM}$ digitonin and $2 \mathrm{mM}$ DTT]. Cell lysates (50 $\mu \mathrm{g}$ protein) were incubated with caspase-3 specific substrates (DEVD-pNA) for $1 \mathrm{~h}$ at $37^{\circ} \mathrm{C}$ and the caspase-3 activity was determined by measuring OD405 of the released pNA as previously described $(23,24)$.

Western blot analysis for examining the associated protein levels in WEHI-3 cells. WEHI-3 cells were placed in $10-\mathrm{cm}$ dishes at the density of $5 \times 10^{5}$ cells $/ \mathrm{ml}$ and were exposed to $300 \mu \mathrm{M}$ of GA for $0,6,12,24$ and $48 \mathrm{~h}$. Then cells from each treatment were harvested and were dissolved in the PRO-PREP ${ }^{\mathrm{TM}}$ protein extraction solution (iNtRON Biotechnology, Seongnam-si, Gyeonggi-do, Korea). All lysed samples were boiled at $100^{\circ} \mathrm{C}$ for 10 min with $4 \mathrm{X}$ protein loading dye. All samples were individually subjected to SDS-polyacrylamide gel electrophoresis as previously described $(9,17)$. All proteins in the gel were transferred onto an Immobilon-P PVDF membrane (Merck Millipore, Bedford, MA, USA) and incubated with the primary antibodies Fas, FasL, caspase-3, Bid, Bax, apoptosis-inducing factor (AIF), cytochrome $c$, Endo G, IRE-1 $\alpha$, calpain 1, caspase-12, GRP 78, SOD $(\mathrm{Cu} / \mathrm{Zn})$, SOD $(\mathrm{Mn})$ and catalase overnight (1:1,000 dilution), were then washed and then were incubated with horseradish peroxide-linked secondary antibody (1:8,000 dilution) and analyzed using the Immobilon Western Chemiluminescent HRP substrate (Millipore) as previously described $(9,25)$.

Confocal laser microscopy. WEHI-3 cells at the density of $5 \times 10^{4}$ cells/well were plated on 4-well chamber slides and were then treated without (control) or with $300 \mu \mathrm{M}$ of GA for $24 \mathrm{~h}$. At the end of incubation, cells were washed with PBS and fixed with $4 \%$ formaldehyde in PBS for $15 \mathrm{~min}$, followed by permeabilization for $1 \mathrm{~h}$ using $0.3 \%$ Triton X-100 in PBS containing $2 \%$ BSA for blocking non-specific binding sites. Cell samples were then stained by anti-AIF, anti-Endo G or anti-cytochrome $c$ antibodies (1:100 dilution, respectively) for $24 \mathrm{~h}$, washed twice with PBS and then stained with a secondary antibody (FITC-conjugated goat anti-mouse IgG at 1:100 dilution) for $40 \mathrm{~min}$, followed by PI staining for DNA analysis. Examinations and photomicrographs were captured using a Leica TCS SP2 Confocal Spectral Microscope, as previously described $(26,27)$. 
A

$24 \mathrm{~h}$
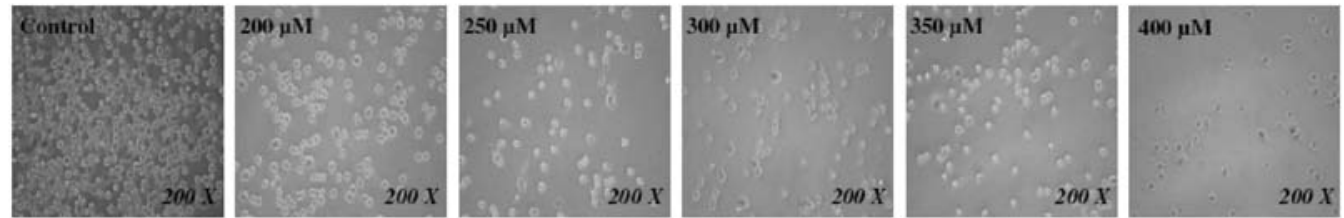

$48 \mathrm{~h}$
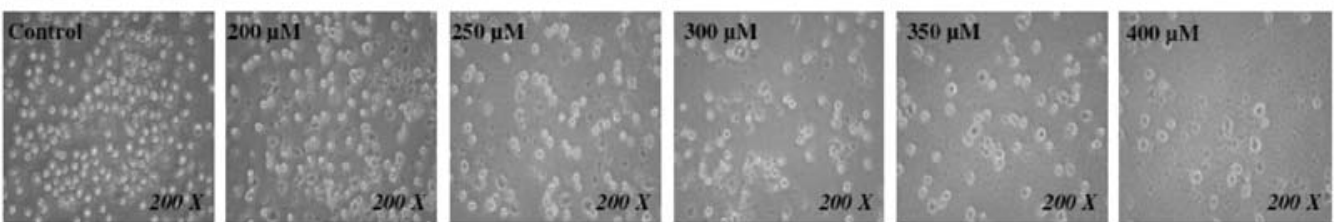

B

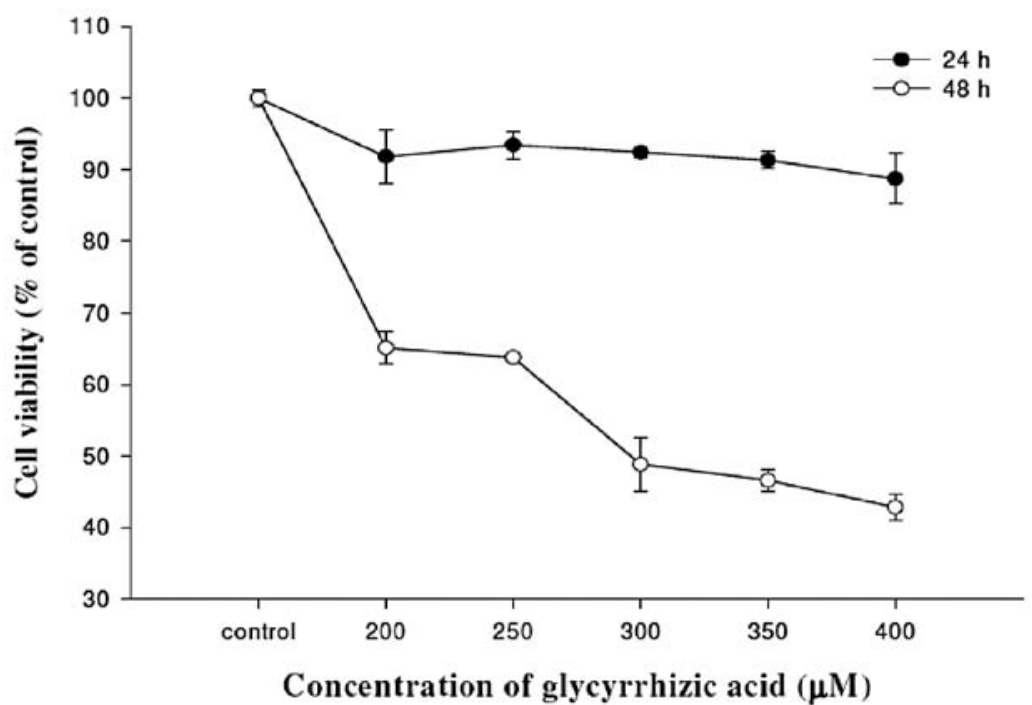

Figure 1. GA induces cell morphological changes and reduces the percentage of viable WEHI-3 mouse leukemia cells. (A) Cells (2x10 5 cells/well) placed in 24-well plates were treated with $0,200,250,300,350$ and $400 \mu \mathrm{M}$ of GA for 24 and $48 \mathrm{~h}$. Cells were examined and images were captured using a contrast phase microscope. (B) All cells from each treatment were harvested and the percentage of viable cells was determined as described in Materials and methods. Data are presented as the means \pm SD in triplicate. $\mathrm{P}<0.05$ indicated a statistically significant difference compared to the GA and DMSO-treated groups.

Statistical analyses. The data from individual experiments are presented as the means \pm SD. The differences between the GA-treated and -untreated (control) groups were analyzed using the Student's $t$-test; a probability of $\mathrm{P}<0.05$ indicated a statistically significant difference.

\section{Results}

GA induces cell morphological changes and decreases the percentage of viable WEHI-3 mouse leukemia cells. WEHI-3 cells were treated with various concentrations (0, 200, 250, 300,350 and $400 \mu \mathrm{M}$ ) of GA or DMSO for 24 and $48 \mathrm{~h}$. Cells were examined and images were captured using a contrastphase microscope at a magnification of $x 200$. The results showed that GA induced cell morphological changes in a dose-dependent manner (Fig. 1A). The percentage of total viable cells in each treatment was determined by flow cytometric assay. Results demonstrated that GA concentrations of 200-400 $\mu \mathrm{M}$ decreased the cell number (inhibited cell growth) in a dose- and time-dependent manner (Fig. 1B).

GA induces $G_{0} / G_{1}$ phase arrest in WEHI-3 cells. Flow cytometry was used for evaluating the cell cycle distribution of WEHI-3 cells with or without GA treatment for 24 and $48 \mathrm{~h}$. As shown in Fig. 2A and B, exposure to 200-400 $\mu \mathrm{M}$ GA caused an increase in the $\mathrm{G}_{0} / \mathrm{G}_{1}$ phase fraction from 39.2 to $72.3 \%$ and from 41.1 to $80.3 \%$, as compared to the control samples following 24 and $48 \mathrm{~h}$ of treatment, respectively. These effects of $G A$ on $G_{0} / G_{1}$ phase arrest were exhibited in a dose- and time-dependent manner. These data suggest that GA-induced $\mathrm{G}_{0} / \mathrm{G}_{1}$ phase arrest accounts for the decrease in the percentage of viable WEHI- 3 cells by GA.

GA induces DNA damage and apoptosis in WEHI-3 cells. DAPI staining and comet assay were used for investigating GA-induced DNA damage and chromatin condensation (apoptosis) of WEHI-3 cells after exposure to various concentrations of GA. GA induced DNA condensation as shown by an increased fluorescent intensity (Fig. 3A) indicating that GA induced apoptosis. GA induced DNA damage as noted by a longer comet tail (Fig. 3B). The higher the GA concentration, the longer the comet tail and the lower the number of cells (Fig. 3B).

GA induces apoptotic death of WEHI-3 cells. After treatment with GA for 24 and 48 h, WEHI-3 cells were harvested for DNA isolation followed by DNA gel electrophoresis (Fig. 4). GA induced DNA fragmentation (DNA ladder) in WEHI-3 cells at all examined concentrations. 
A

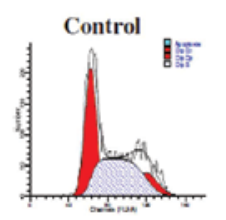

$300 \mu \mathrm{M}$
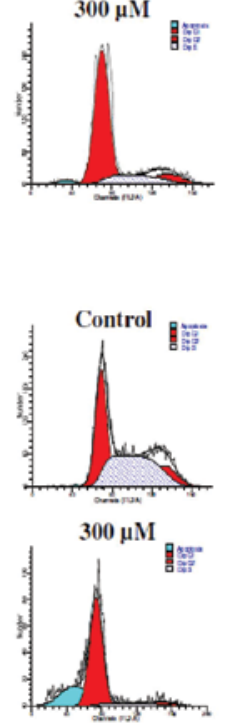

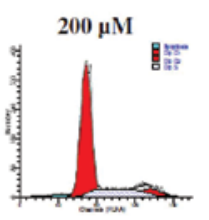

$350 \mu \mathrm{M}$

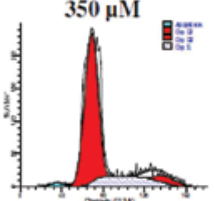

醴

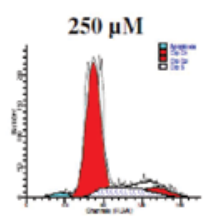

$400 \mu \mathrm{M}$
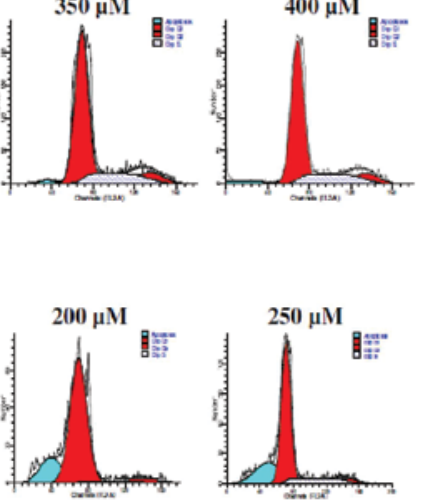

$350 \mu \mathrm{M}$

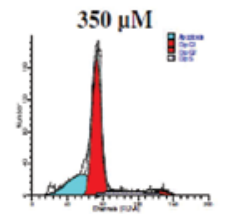

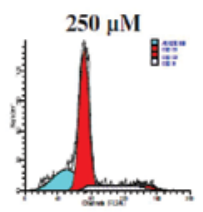

$400 \mu \mathrm{M}$

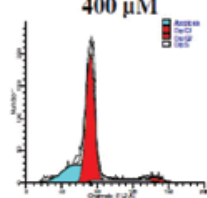

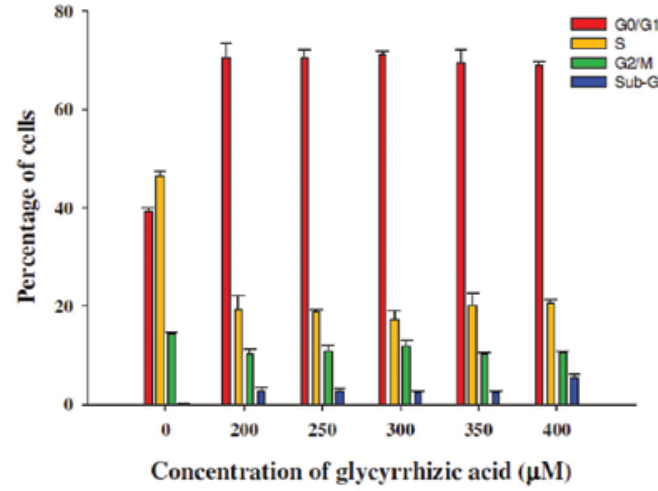

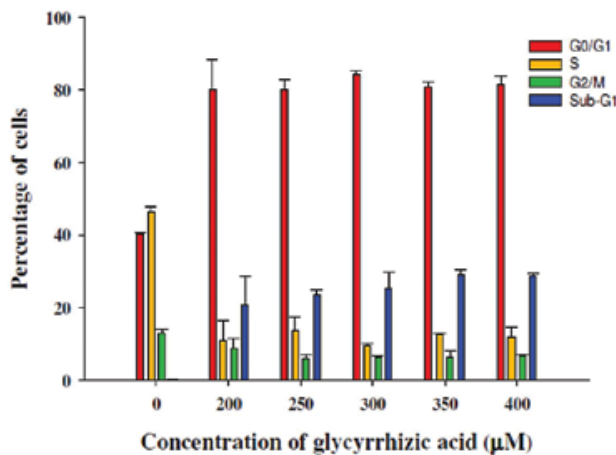

Figure 2. GA induces $\mathrm{G}_{0} / \mathrm{G}_{1}$ phase arrest in WEHI-3 cells. Cells at a density of $2 \times 10^{5}$ cells/well were placed in $24-w e l l$ plates and were then treated with 0 , $200,250,300,350$ and $400 \mu \mathrm{M}$ of GA for 24 and $48 \mathrm{~h}$. Cells were harvested for measuring the cell cycle distribution by flow cytometric assay as described in Materials and methods. The representative of profiles of DNA content and the percentage of cells in $\mathrm{G}_{0} / \mathrm{G}_{1}, \mathrm{~S}$ and $\mathrm{G}_{2} / \mathrm{M}_{\mathrm{phase}}$ in WEHI-3 cells at $24 \mathrm{~h}(\mathrm{~A})$ and $48 \mathrm{~h}$ (B) following GA treatment. Data are representative of 3 experiments with similar results.

A
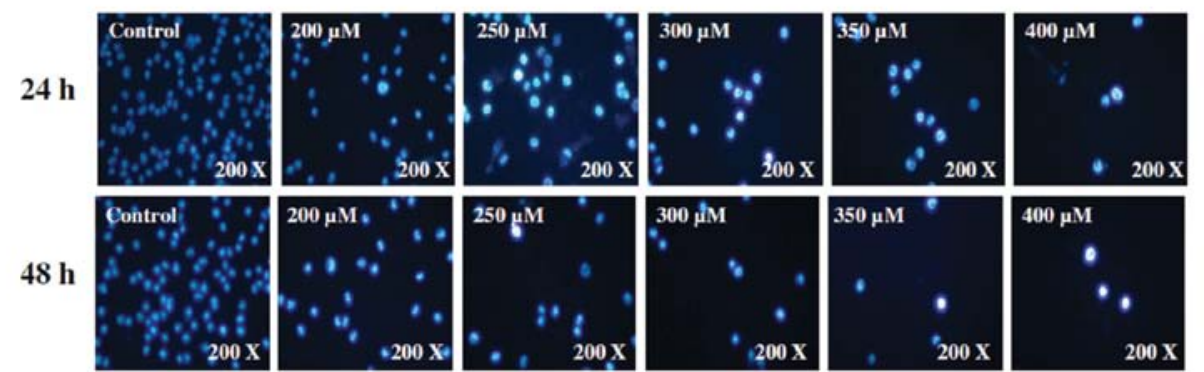

$48 \mathrm{~h}$

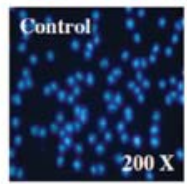

B
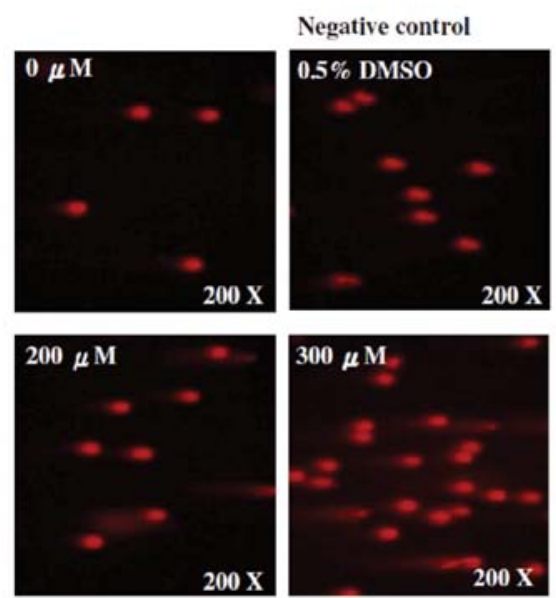

Positive control
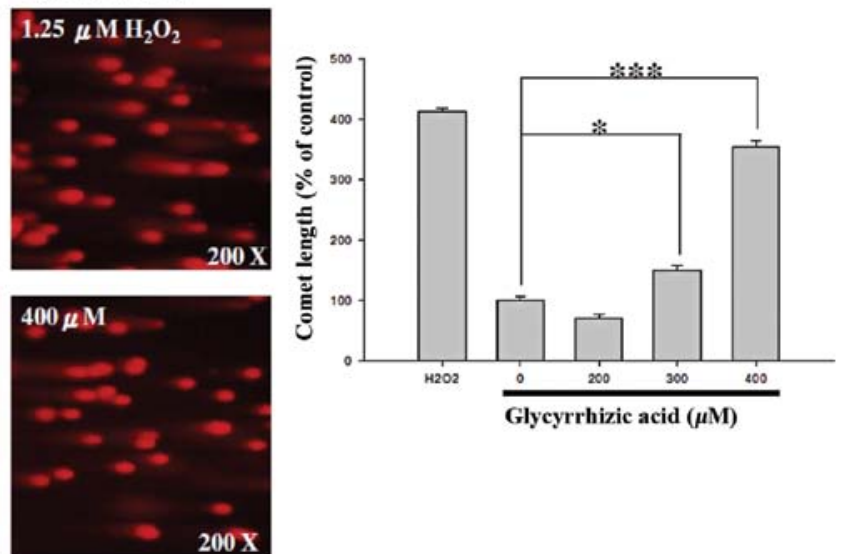

Figure 3. GA induces apoptosis and DNA damage in WEHI-3 cells. Cells (2x10 5 cells/well) were placed in $24-w e l l$ plates and grown for 24 h. The cells were incubated with $0,200,250,300,350$ and $400 \mu \mathrm{M}$ of GA for $24 \mathrm{~h}$ and and $48 \mathrm{~h}$ were then isolated for the examination of apoptosis using DAPI staining (A); or for the examination of DNA damage using the comet assay (B). Images were captured under fluorescence microscopy as in Materials and methods. * $\mathrm{P}<0.05$ and ${ }^{* * *} \mathrm{P}<0.001$ show a significant difference. 

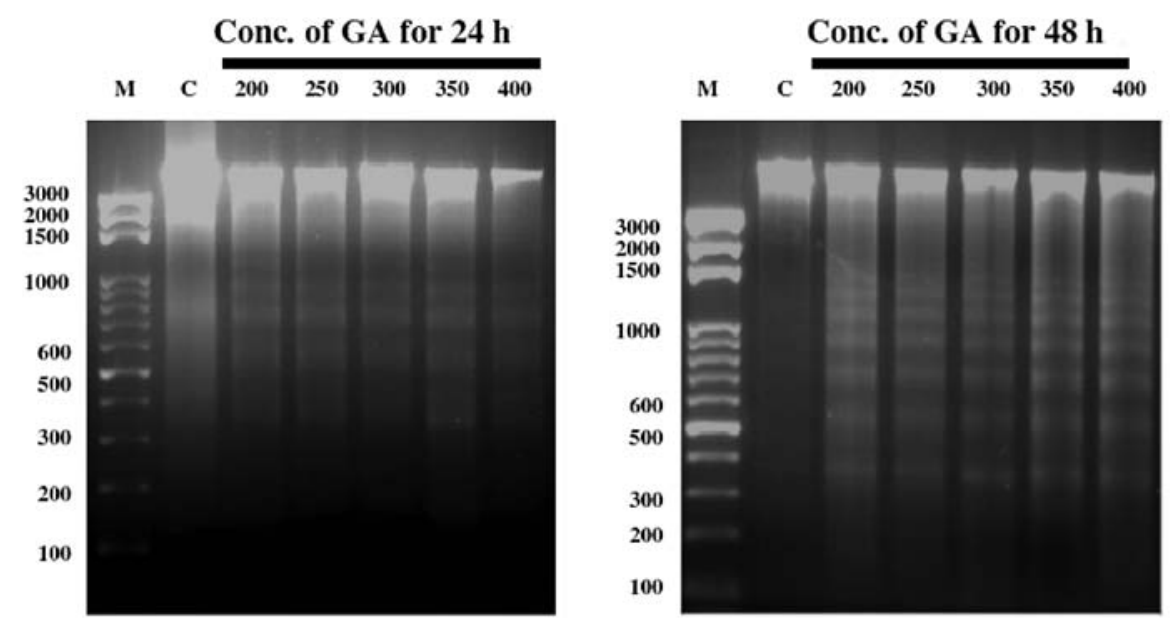

Figure 4. GA induces DNA fragmentations of WEHI-3 cells. Cells $\left(1 \times 10^{6}\right.$ cells/dish) were placed in 10-cm dishes and were treated with 0, 200, 250, 300, 350 and $400 \mu \mathrm{M}$ of GA for $24 \mathrm{~h}$ (Left) and $48 \mathrm{~h}$ (Right) to examine apoptosis. Cells were harvested for DNA isolation and then DNA gel electrophoresis was performed as described in Materials and methods.

A

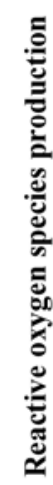

है

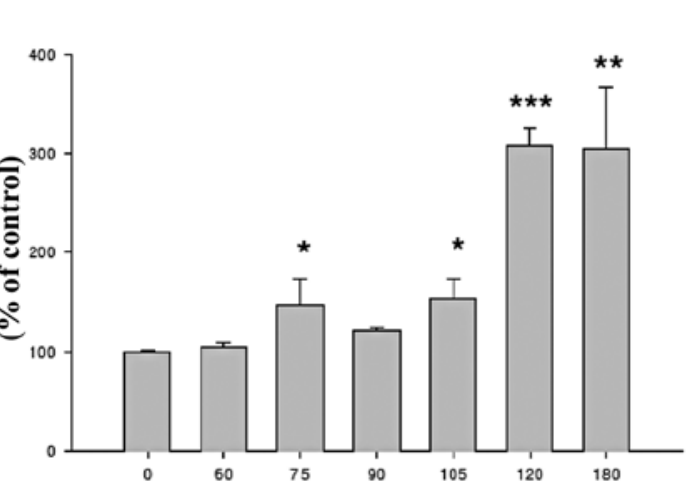

Time of incubation $(\mathrm{min})$
B

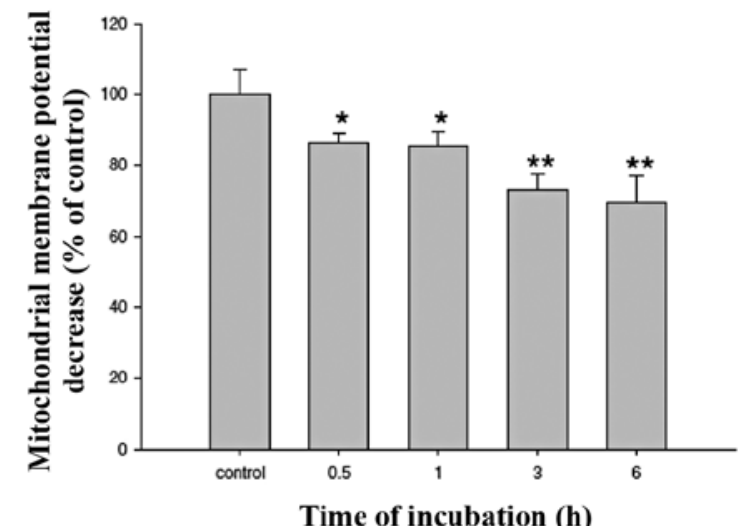

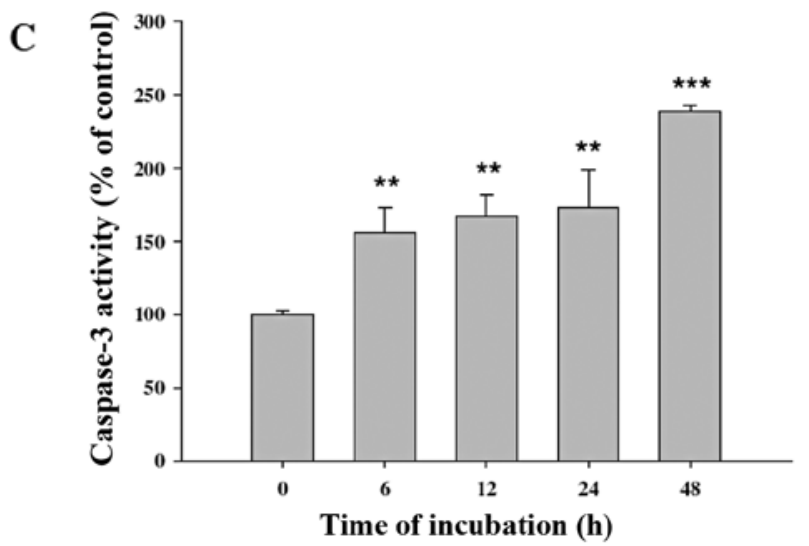

Figure 5. GA affects reactive oxygen species (ROS) production, decreases the level of mitochondrial membrane potential ( $\Delta \Psi \mathrm{m})$ and promotes caspase-3 activity in WEHI-3 cells. Cells $\left(2 \times 10^{5}\right.$ cells/well) in 24 -well plates were treated with or without $300 \mu \mathrm{M}$ of GA for various time periods and were harvested and re-suspended in $500 \mu 1$ of $\mathrm{H}_{2}$ DCF-DA for determination of ROS (A); DiOC 6 for assessment of $\Delta \Psi \mathrm{m}(\mathrm{B})$; and caspase-3 substrate solution for determination of caspase-3 activity (C). Cells were then incubated at $37^{\circ} \mathrm{C}$ for $30 \mathrm{~min}$ and were analyzed by flow cytometry as described in Materials and methods. Columns, mean $(\mathrm{n}=3)$; bars, $\mathrm{SD} .{ }^{*} \mathrm{P}<0.05$ and ${ }^{* * *} \mathrm{P}<0.001$ indicate a significant difference compared with the control.

GA affects reactive oxygen species (ROS) production, decreases the level of $\triangle \Psi m$ and promotes caspase-3 activity in WEHI-3 cells. WEHI- 3 cells were treated with $300 \mu \mathrm{M}$ GA for various time periods and were then harvested for the measure- ments of ROS production, the levels of $\Delta \Psi \mathrm{m}$ and caspase-3 activity. GA promoted the production of ROS (Fig. 5A) and caspase-3 activities (Fig. 5C) but decreased the levels of $\Delta \Psi \mathrm{m}$ (Fig. 5B) in WEHI-3 cells. 

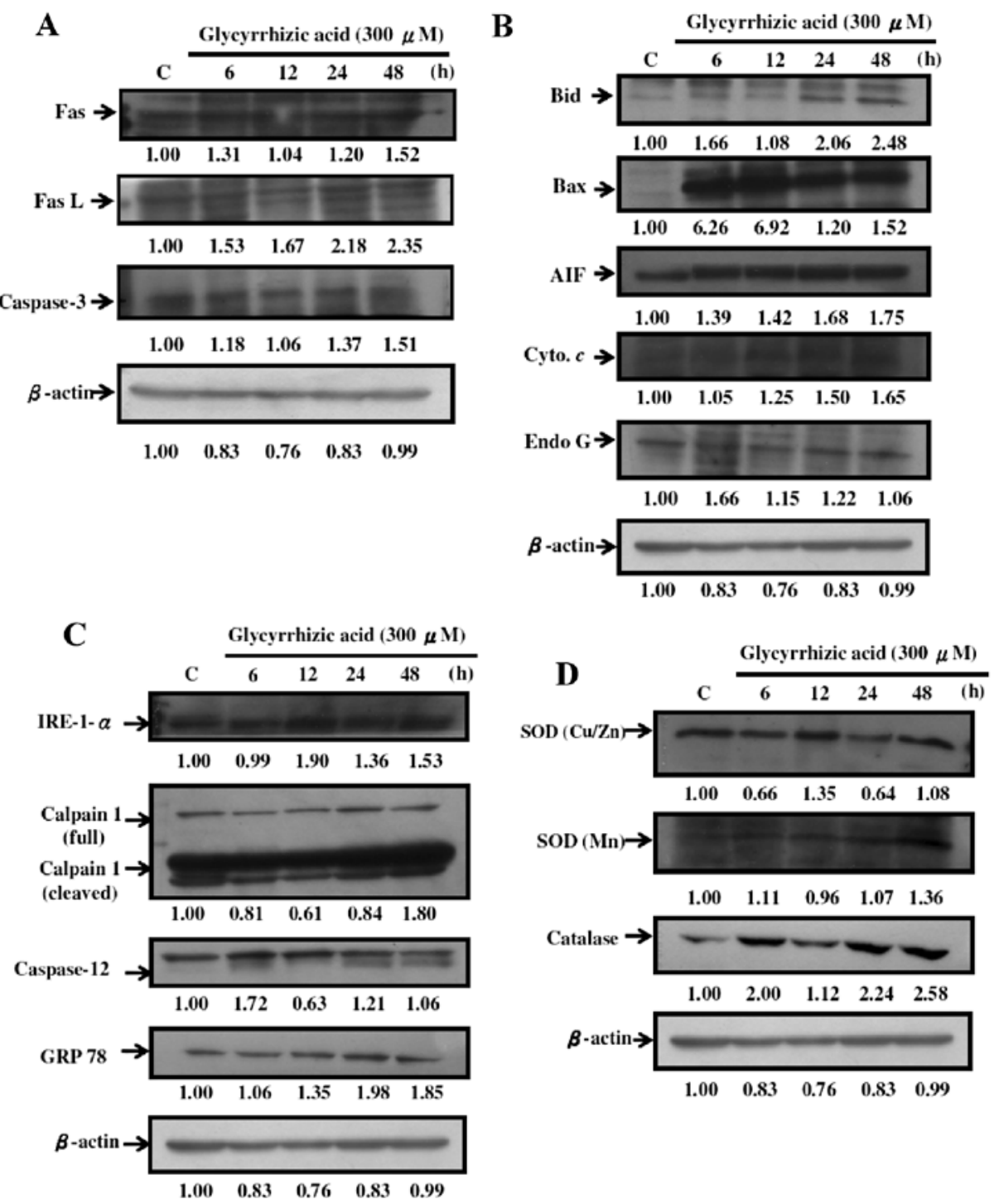

Figure 6. GA affects apoptosis-associated proteins in WEHI-3 cells. Cells ( $1 \times 10^{6}$ cells/dish) seeded in 10 -cm dishes were then treated with $300 \mu \mathrm{M}$ of GA and were incubated for 0, 6, 12, 24, 36 and 48 h. Cells were harvested for western blotting to examine the protein levels of Fas, Fas L and caspase-3 (A); Bid, Bax, AIF, cytochrome $c$ and Endo G (B); IRE-1- $\alpha$, calpain-1 (full and cleaved), caspase-12 and GRP 78 (C); catalase, SOD (Cu/Zn) and SOD (Mn) (D) as described in Materials and methods.

GA affects levels of apoptosis-associated proteins in WEHI-3 cells. Cells treated with GA were then harvested for determination of apoptotic-associated protein levels by using western blotting. Results indicated that GA promoted the protein expression of Fas, FasL and caspase-3 (Fig. 6A); Bid, Bax, AIF, cytochrome $c$ and Endo G (Fig. 6B); IRE-1- $\alpha$, calpain-1, caspase-12 and GRP 78 (Fig. 6C); catalase, SOD (Cu/Zn) and SOD (Mn) (Fig. 6D). This indicated that GA induced apoptosis in WEHI-3 cells through caspase-dependent, ER stress and mitochondria-dependent pathways.

$G A$ affects the AIF, cytochrome $c$ and Endo $G$ expression in WEHI-3 cells. Cells were treated with GA for $24 \mathrm{~h}$ and the expression levels of AIF, cytochrome $c$ and Endo G were examined (Fig. 7). GA promoted the release of AIF, cytochrome $c$ and Endo $G$ from mitochondria. These results indicated that GA induced apoptosis in WEHI-3 cells via a mitochondriadependent pathway.

\section{Discussion}

Although numerous studies have shown that GA induces cytotoxic effects in many type of cancer cells $(10,15,28,29)$, there is no report demonstrating that GA induces apoptosis in mouse leukemia cells. In the present study, we investigated the effects of GA on mouse leukemia WEHI-3 cells and the results indicated that GA decreased the percentage of viable cells and induced apoptosis in WEHI-3 cells. Furthermore, we also demonstrated that GA induced ROS production (Fig. 5A) and decreased the levels of $\Delta \Psi \mathrm{m}$ (Fig. 5B) which was assayed by flow cytometry.

It is well documented that apoptosis may be divided into caspase-dependent and -independent pathways $(30,31)$. The results in the present study indicate that GA decreased the percentage of viable cells through the induction of apoptosis based on the observations of DAPI staining (Fig. 3A) and flow cytometric assay (Fig. 2). Additionally, ROS is known to be 
A
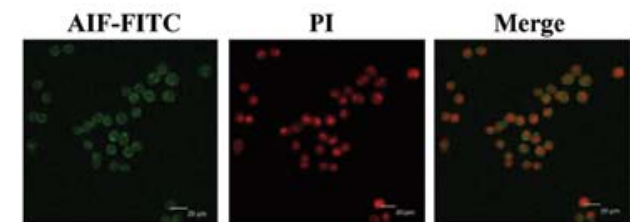

GA $(300 \mu \mathrm{M})$
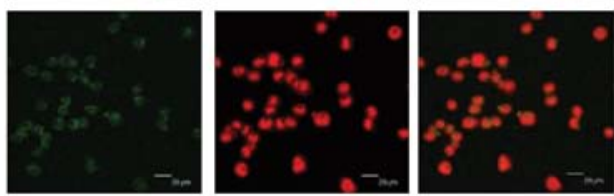

B

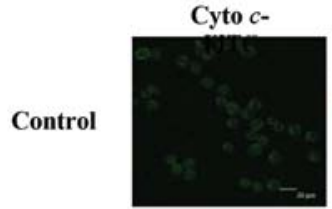

MitoTracker

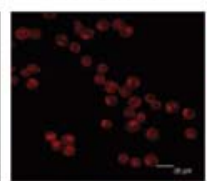

GA $(300 \mu \mathrm{M})$
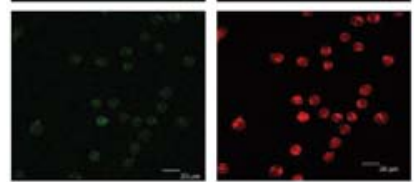

PI

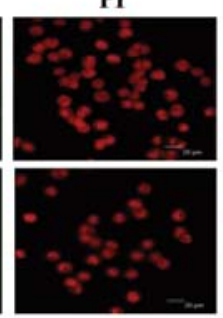

Merge
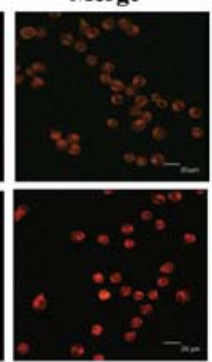

C

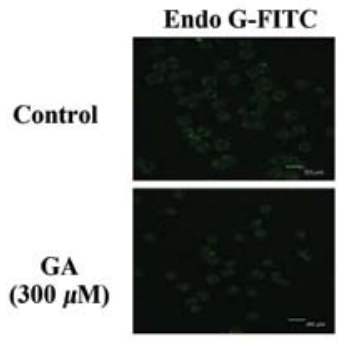

Figure 7. GA affects the AIF, cytochrome $c$ and Endo $\mathrm{G}$ expression in WEHI- 3 cells. Cells ( $5 \times 10^{4}$ cells/well) placed on 4 -well chamber slides were treated with $300 \mu \mathrm{M}$ of GA for $24 \mathrm{~h}$, fixed and stained using anti-AIF, anticytochrome $c$ and anti-Endo G (1:100) overnight and then stained with a secondary antibody (FITC-conjugated goat anti-mouse IgG at 1:100 dilution) (green fluorescence) followed by mitochondrial and nuclear counterstaining individually performed with MitoTracker ${ }^{\circledR}$ Red CMXRos (Molecular Probes) and PI (red fluorescence). Photomicrographs were obtained using a Leica TCS SP2 confocal spectral microscope as described in Materials and methods.

involved in the induction of apoptosis after cells are exposed to various compounds $(32,33)$. Our results (Fig. 5A) demonstrated that GA promoted ROS production in WEHI-3 cells. These results indicated that GA induced apoptosis via ROS production. The ER stress pathway is also another possible signaling pathway involved in agent-induced apoptosis in cancer cells $(34,35)$. The hallmarkers of ER stress, such as the expression of GRP 78 and GADD153 are able to activate caspase-12 and IRE-1 $\alpha$ (34-36). In the present study, we also found that GA promoted the expression of GRP78 (Fig. 6C) and GADD153 (data not shown) which was measured by western blotting. We suggested that GA induced apoptosis in part through ER stress.

It is well documented that agent-induced cancer cell apoptosis occurs through a mitochondria-dependent pathway (31). We also observed that GA decreased the levels of $\Delta \Psi \mathrm{m}$ in WEHI-3 cells (Fig. 5B) in a time-dependent manner. Furthermore, results from western blotting also showed that GA promoted the expression of cytochrome $c$, AIF and Endo $G$ which are released from mitochondria (Fig. 6). Thus, we suggest that GA induces apoptosis, in part, through the caspase-independent and mitochondria-dependent pathways. These findings also were confirmed using a confocal laser systems microscope which demonstrated that GA promoted the release of AIF, cytochrome $c$ and Endo G (Fig. 6B).

Overall, our study showed that the natural compound GA acts as an apoptosis-inducing agent against mouse leukemia cells in vitro. In our WEHI-3 mouse leukemia cell study, GA not only induced cytotoxic effects, but also suppressed cell growth and induced apoptosis (Fig. 8). This highly correlates with the inhibition of numerous biomarkers linked to apoptosis via caspase-dependent and -independent, ER stress and mitochondria-dependent pathways.

\section{Acknowledgements}

This study was supported by the grant CMU100-ASIA-4 from the China Medical University and by the Taiwan Department

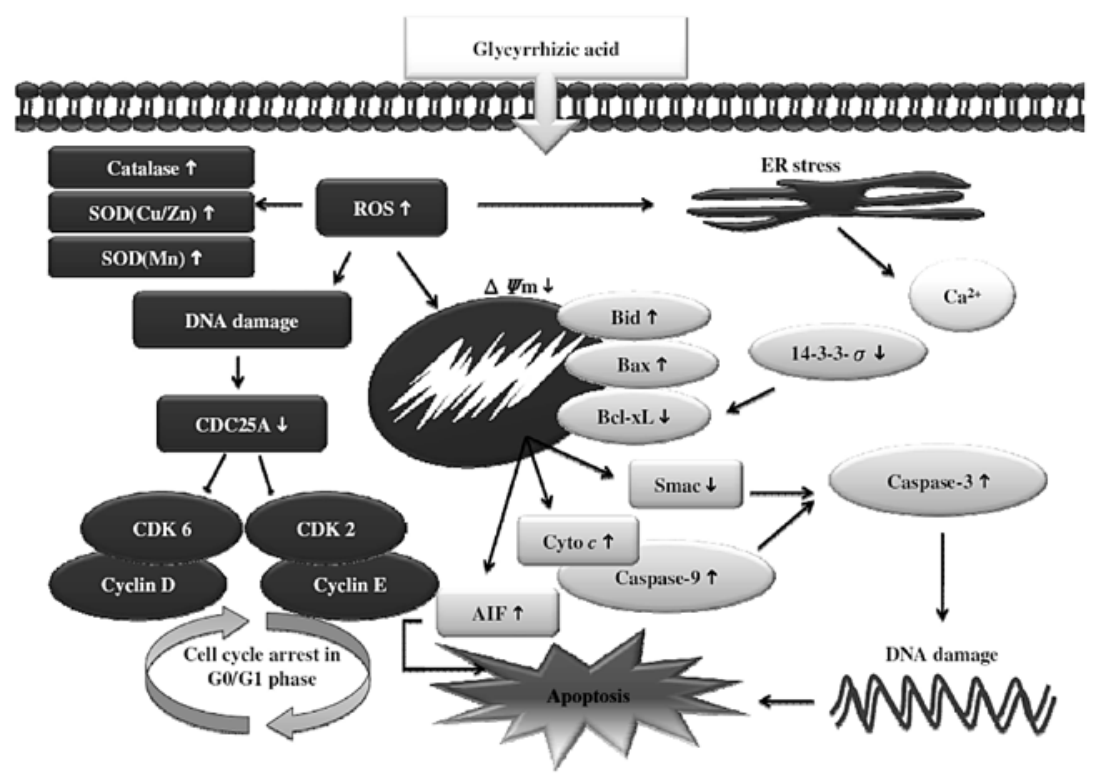

Figure 8. The possible signaling pathways for GA-induced apoptosis through ROS, ER stress, caspase-3- and mitochondria-dependent pathways in mouse leukemia WEHI-3 cells. 
of Health, China Medical University Hospital Cancer Research Center of Excellence (DOH101-TD-C-111-005).

\section{References}

1. Lee SJ, Kim KH, Park JS, et al: Comparative analysis of cell surface proteins in chronic and acute leukemia cell lines. Biochem Biophys Res Commun 357: 620-626, 2007.

2. Stahnke K, Eckhoff S, Mohr A, Meyer LH and Debatin KM: Apoptosis induction in peripheral leukemia cells by remission induction treatment in vivo: selective depletion and apoptosis in a $\mathrm{CD}^{+}{ }^{+}$subpopulation of leukemia cells. Leukemia 17: 2130-2139, 2003.

3. Lu CC, Yang JS, Chiang JH, et al: Novel quinazolinone MJ-29 triggers endoplasmic reticulum stress and intrinsic apoptosis in murine leukemia WEHI-3 cells and inhibits leukemic mice. PLoS One 7: e36831, 2012.

4. Lin JP, Yang JS, Lin JJ, et al: Rutin inhibits human leukemia tumor growth in a murine xenograft model in vivo. Environ Toxicol 27: 480-484, 2012.

5. Sack H: Leukemia in patients with breast carcinoma after adjuvant chemotherapy and/or postoperative radiotherapy. Strahlenther Onkol 171: 420-421, 1995.

6. Liu W, Lee HW, Liu Y, Wang R and Rodgers GP: Olfactomedin 4 is a novel target gene of retinoic acids and 5-aza-2'-deoxycytidine involved in human myeloid leukemia cell growth, differentiation, and apoptosis. Blood 116: 4938-4947, 2010.

7. Sakoe Y, Sakoe K, Kirito K, Ozawa K and Komatsu N: FOXO3A as a key molecule for all-trans retinoic acid-induced granulocytic differentiation and apoptosis in acute promyelocytic leukemia. Blood 115: 3787-3795, 2010.

8. Evan G and Littlewood T: A matter of life and cell death. Science 281: 1317-1322, 1998

9. Chiang JH, Yang JS, Ma CY, et al: Danthron, an anthraquinone derivative, induces DNA damage and caspase cascade-mediated apoptosis in SNU-1 human gastric cancer cells through mitochondrial permeability transition pores and Bax-triggered pathways. Chem Res Toxicol 24: 20-29, 2011.

10. Ploeger B, Mensinga T, Sips A, Seinen W, Meulenbelt J and DeJongh J: The pharmacokinetics of glycyrrhizic acid evaluated by physiologically based pharmacokinetic modeling. Drug Metab Rev 33: 125-147, 2001.

11. Yim SB, Park SE and Lee CS: Protective effect of glycyrrhizin on 1-methyl-4-phenylpyridinium-induced mitochondrial damage and cell death in differentiated PC12 cells. J Pharmacol Exp Ther 321: 816-822, 2007.

12. Schrofelbauer B, Raffetseder J, Hauner M, Wolkerstorfer A, Ernst W and Szolar OH: Glycyrrhizin, the main active compound in liquorice, attenuates pro-inflammatory responses by interfering with membrane-dependent receptor signalling. Biochem J 421: 473-482, 2009.

13. Cherng JM, Lin HJ, Hung MS, Lin YR, Chan MH and Lin JC: Inhibition of nuclear factor kappaB is associated with neuroprotective effects of glycyrrhizic acid on glutamate-induced excitotoxicity in primary neurons. Eur J Pharmacol 547: 10-21, 2006.

14. Kao TC, Shyu MH and Yen GC: Neuroprotective effects of glycyrrhizic acid and 18beta-glycyrrhetinic acid in PC12 cells via modulation of the PI3K/Akt pathway. J Agric Food Chem 57: 754-761, 2009.

15. Tripathi M, Singh BK and Kakkar P: Glycyrrhizic acid modulates t-BHP induced apoptosis in primary rat hepatocytes. Food Chem Toxicol 47: 339-347, 2009.

16. Kim SW, Jin Y, Shin JH, et al: Glycyrrhizic acid affords robust neuroprotection in the postischemic brain via anti-inflammatory effect by inhibiting HMGB1 phosphorylation and secretion. Neurobiol Dis 46: 147-156, 2012.
17. Lu CC, Yang JS, Huang AC, et al: Chrysophanol induces necrosis through the production of ROS and alteration of ATP levels in J5 human liver cancer cells. Mol Nutr Food Res 54: 967-976, 2010.

18. Ji BC, Hsu WH, Yang JS, et al: Gallic acid induces apoptosis via caspase- 3 and mitochondrion-dependent pathways in vitro and suppresses lung xenograft tumor growth in vivo. J Agric Food Chem 57: 7596-7604, 2009.

19. Yu FS, Yang JS, Yu CS, et al: Safrole induces apoptosis in human oral cancer HSC-3 cells. J Dent Res 90: 168-174, 2011.

20. Kuo CL, Wu SY, Ip SW, et al: Apoptotic death in curcumintreated NPC-TW 076 human nasopharyngeal carcinoma cells is mediated through the ROS, mitochondrial depolarization and caspase-3-dependent signaling responses. Int J Oncol 39: 319-328, 2011.

21. Chung JG, Yang JS, Huang LJ, et al: Proteomic approach to studying the cytotoxicity of YC-1 on U937 leukemia cells and antileukemia activity in orthotopic model of leukemia mice. Proteomics 7: 3305-3317, 2007.

22. Petronilli V, Miotto G, Canton M, et al: Transient and long-lasting openings of the mitochondrial permeability transition pore can be monitored directly in intact cells by changes in mitochondrial calcein fluorescence. Biophys J 76: 725-734, 1999.

23. Huang WW, Chiu YJ, Fan MJ, et al: Kaempferol induced apoptosis via endoplasmic reticulum stress and mitochondriadependent pathway in human osteosarcoma U-2 OS cells. Mol Nutr Food Res 54: 1585-1595, 2010.

24. Yang JS, Hour MJ, Huang WW, Lin KL, Kuo SC and Chung JG: MJ-29 inhibits tubulin polymerization, induces mitotic arrest, and triggers apoptosis via cyclin-dependent kinase 1-mediated Bcl-2 phosphorylation in human leukemia U937 cells. J Pharmacol Exp Ther 334: 477-488, 2010.

25. Lai TY, Yang JS, Wu PP, et al: The quinolone derivative CHM-1 inhibits murine WEHI-3 leukemia in BALB/c mice in vivo. Leuk Lymphoma 51: 2098-2102, 2010.

26. Lu HF, Lai KC, Hsu SC, et al: Curcumin induces apoptosis through FAS and FADD, in caspase-3-dependent and -independent pathways in the N18 mouse-rat hybrid retina ganglion cells. Oncol Rep 22: 97-104, 2009.

27. Wu SH, Hang LW, Yang JS, et al: Curcumin induces apoptosis in human non-small cell lung cancer NCI-H460 cells through ER stress and caspase cascade- and mitochondria-dependent pathways. Anticancer Res 30: 2125-2133, 2010.

28. Zhao MX, Ji LN and Mao ZW: $\beta$-Cyclodextrin/glycyrrhizic acid functionalised quantum dots selectively enter hepatic cells and induce apoptosis. Chemistry 18: 1650-1658, 2012.

29. Curreli F, Friedman-Kien AE and Flore O: Glycyrrhizic acid alters Kaposi sarcoma-associated herpesvirus latency, triggering p53-mediated apoptosis in transformed B lymphocytes. J Clin Invest 115: 642-652, 2005.

30. Kelloff GJ, Crowell JA, Steele VE, et al: Progress in cancer chemoprevention: development of diet-derived chemopreventive agents. J Nutr 130: S467-S471, 2000.

31. Lavrik IN, Golks A and Krammer PH: Caspases: pharmacological manipulation of cell death. J Clin Invest 115: 2665-2672, 2005.

32. Green DR and Reed JC: Mitochondria and apoptosis. Science 281: 1309-1312, 1998.

33. Orrenius S: Reactive oxygen species in mitochondria-mediated cell death. Drug Metab Rev 39: 443-455, 2007.

34. Kadowaki H, Nishitoh $\mathrm{H}$ and Ichijo $\mathrm{H}$ : Survival and apoptosis signals in ER stress: the role of protein kinases. J Chem Neuroanat 28: 93-100, 2004.

35. Oyadomari S and Mori M: Roles of CHOP/GADD153 in endoplasmic reticulum stress. Cell Death Differ 11: 381-389, 2004

36. Rao RV, Ellerby HM and Bredesen DE: Coupling endoplasmic reticulum stress to the cell death program. Cell Death Differ 11: 372-380, 2004. 